\section{Heat Therapy With Relevance to the Reversal of NAFLD and Diabetes}

\author{
lan J Martins $\mathbf{~}^{* 1,2,3}$ \\ ${ }^{1}$ Centre of Excellence in Alzheimer's Disease Research and Care, School \\ of Medical Sciences, Edith Cowan University, Australia \\ ${ }^{2}$ School of Psychiatry and Clinical Neurosciences, The University of West- \\ ern Australia, Australia \\ ${ }^{3}$ McCusker Alzheimer's Research Foundation, Holywood Medical Centre, \\ Australia
}

Keywords: Bacterial lipopolysaccharides; Cardiovascular disease; Heat shock factor 1; Heat therapy; Heat shock gene; Heat shock protein; NAFLD; Sirtuin 1; Transcriptional dysregulation

\section{Abbreviations}

Sirtuin 1 (Sirt 1), Heat Shock Proteins (HSP), Heat Shock Factor 1 (HSF1), Non Alcoholic Fatty Liver Disease (NAFLD), Bacterial Lipopolysaccharides (LPS), AMP-Activated Protein Kinase (AMPK)

\section{Editorial}

The use of heat therapy in individuals with obesity and Type 2 diabetes mellitus has become an important treatment for metabolic and cardiovascular diseases [1-5] for individuals in the developing and developed world. The cellular response to heat therapy includes the transcriptional up-regulation of genes encoding Heat Shock Proteins (HSPs) as part of the cell's internal repair mechanism [6,7]. These stress-proteins respond to heat, cold and oxygen deprivation by activating several cascade pathways that may be relevant to survival and apoptosis of mitochondria in cells [8]. Heat therapy has been used with the plasma analysis of adiponectin, AMP-Activated Protein Kinase (AMPK), Heat Shock Factor 1 (HSF1), Heat Shock Protein (HSP) 27, HSP70, and HSP90 important as markers for heat stress therapy [9]. Diabetes that previously has involved pancreatic disease in Type 2 diabetic individuals [10] now involves global Non Alcoholic Fatty Liver Disease (NAFLD) with heat therapy critical to improvement in hepatic insulin resistance [11] in obese/diabetic individuals. Heat

*Corresponding author: Ian J Martins, Centre of Excellence in Alzheimer's Disease Research and Care, School of Medical Sciences, Edith Cowan University, 270 Joondalup Dr, Joondalup WA 6027, Australia, Tel: +61 863042574; E-mail: i.martins@ecu.edu.au

Citation: Martins IJ (2017) Heat Therapy With Relevance to the Reversal of NAFLD and Diabetes. J Diabetes Metab Disord 4: 018.

Received: February 08, 2017; Accepted: February 09, 2017; Published: February 23, 2017

Copyright: (c) 2017 Martins IJ, This is an open-access article distributed under the terms of the Creative Commons Attribution License, which permits unrestricted use, distribution, and reproduction in any medium, provided the original author and source are credited. therapy in individuals with NAFLD has now become important to increase hepatic fat metabolism and to improve insulin resistance in these individuals [12]. Plasma bacterial Lipopolysaccharides (LPS) have risen markedly [13] in individuals in the developing world and the relationship between LPS and the repression of the heat shock gene Sirtuin 1 (Sirt 1) has been reported with relevance to NAFLD and diabetes [14-17]. LPS induces NAFLD and the relevance of dietary fat such as virgin coconut oil/palm oil consumption [14] should be carefully controlled to prevent insulin resistance and accelerated NAFLD. Individuals in the developing world are more susceptible to NAFLD and diabetes and the heat shock response by LPS is involved in the transformation of liver cells (NAFLD) [13] and associated with defective heat stress response that involves the Sirt 1/HSF1 interaction [18]. Sirt 1 (NAD+ dependent class III histone deacetylase) is important to the deacetylation of HSF1 [19-23] and hepatic HSP metabolism $[12,15]$ with relevance to in heat therapy in NAFLD and diabetes (Figure 1). Sirt 1 is involved with the circadian regulation of HSP 60, 70 and 90 with temperature regulation closely associated with Sirt 1 activity/HSP levels in cells [24-26] and may be relevant to the heat shock response in Type 2 diabetes. The metabolism of HSP is relevant to insulin resistance with HSP linked to amyloid beta metabolism [10] with relevance to insulin receptor interactions [27-37]. Sirt 1 and transcriptional dysregulation [16] has become of major concern with p53 regulation of HSF1 and mircroRNA-34a (mir-34a) relevant to the heat shock response (Figure 1) $[38,39]$. Sirt 1 is involved in the deacetylation of the transcription factor p53 [16] with heat therapy linked to the induction of p53 related cell apoptosis [40-41]. Sirt 1 is involved with various markers of heat stress such as adiponectin transcription [42], AMPK connections [43], HSF1 regulation and HSP metabolism. AMPK-Sirt 1 (Figure 1) [43] is involved with Nitric Oxide (NO)/HSP crosstalk [44-46] with relevance to natural killer cell activity and the induction of NAFLD $[47,48]$. LPS has been shown to induce HSPs in various cells [49-51] and LPS in various species has been shown to induce thermo regulatory dysfunction $[52,53]$. Heat therapy and the involvement of Sirt 1 has become of importance with relevance to the treatment of heart disease $[4,5]$ and NAFLD in diabetes. LPS is involved in the induction of cardiovascular disease [54] and its effects on the repression of Sirt 1 have raised concern on the use of heat treatment in diabetic individuals in the developing world. LPS is involved in the interference in Sirt 1's role in the deacetylationof p53/mir-34a/ HSF1 (Figure 1) [55] with the effects of heat therapy relevant to the immune response [56,57] and accelerated apoptosis in various cells and tissues. The role of LPS in thermodysregulation involves Sirt 1 dysregulation [16] with temperature regulation by Sirt 1 now relevant to the regulation of $\mathrm{p} 53$ with heat shock protein associated with $\mathrm{p} 53$ accumulation [58].

\section{Conclusion}

The understanding of cellular gene response to heat therapy has accelerated with the global epidemic in obesity and diabetes that is related to chronic diseases such as cardiovascular disease and NAFLD. Heat therapy that involves Sirt 1 should be carefully assessed with relevance to Sirt 1's transcriptional regulation of HSF1/HSP interactions and with excessive heat therapy may accelerate Sirt 1 mediated HSP induced cell apoptosis. Heat therapy to maintain glucose homeostasis 


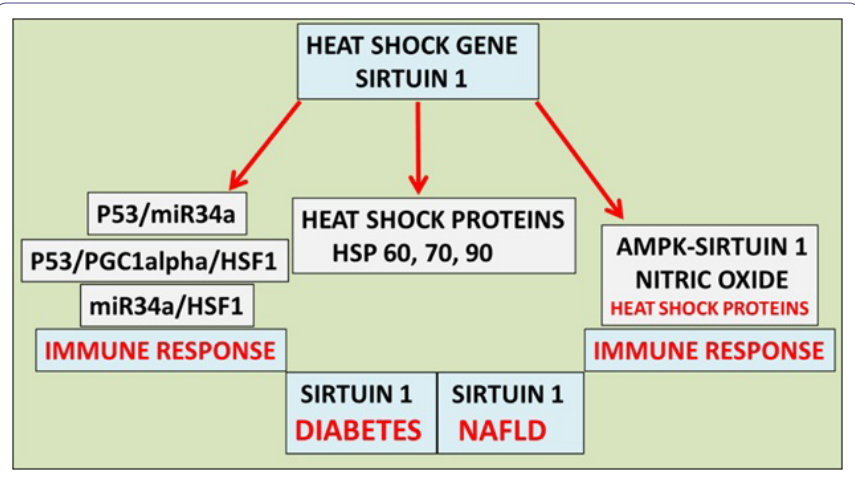

Figure 1: Heat therapy has become important to the treatment of global NAFLD and cardiovascular disease in individuals with diabetes. Heat therapy now involves the heat shock gene Sirt 1 that is involved in the metabolism of Heat Shock Proteins (HSPs), deacetylation of p53 (heat shock factor 1 response) and nitric oxide/HSP homeostasis involved with the immune response and programmed cell death.

in diabetic individuals in the developed world may differ from developing word diabetic individuals that lack the heat shock gene Sirt 1. Heat therapy intervals that involve sauna versus hot tub temperatures should be carefully reassessed for safety with relevance to time limits for heat therapy that may last for weeks/months. Healthy diets that do not contain saturated fats with heat therapy may prevent global NAFLD but heat therapy in these individuals may be more successful with the consumption of Sirt 1 activators versus Sirt 1 inhibitors with relevance to the reversal of global NAFLD and diabetes.

\section{Acknowledgement}

This work was supported by grants from Edith Cowan University, the McCusker Alzheimer's Research Foundation, and the National Health and Medical Research Council.

\section{References}

1. Krause M, Ludwig MS, Heck TG, Takahashi HK (2015) Heat shock proteins and heat therapy for type 2 diabetes: pros and cons. Curr Opin Clin Nutr Metab Care 18: 374-380.

2. Padmalayam I (2014) The heat shock response: its role in pathogenesis of type 2 diabetes and its complications, and implications for therapeutic intervention. Discov Med 18: 29-39.

3. Gupte AA, Bomhoff GL, Swerdlow RH, Geiger PC (2009) Heat treatment improves glucose tolerance and prevents skeletal muscle insulin resistance in rats fed a high-fat diet. Diabetes 58: 567-578.

4. Weber AA, Silver MA (2007) Heat therapy in the management of heart failure. Congest Heart Fail 13: 81-83.

5. Cui J, Sinoway LI (2014) Cardiovascular responses to heat stress in chronic heart failure. Curr Heart Fail Rep 11: 139-145.

6. Stephanou A, Latchman DS (2011) Transcriptional modulation of heat-shock protein gene expression. Biochem Res Int 2011: 238601.

7. Arya R, Mallik M, Lakhotia SC (2007) Heat shock genes - integrating cell survival and death. J Biosci 32: 595-610.

8. Martins IJ (2017) Drug-Drug Interactions with Relevance to Drug Induced Mitochondrial Toxicity and Accelerated Global Chronic Diseases. EC Pharmacology and Toxicology 3: 18-21.

9. Min LI, Cheng JB, Shi BL, Yang HJ, Zheng N, et al. (2015) Effects of heat stress on serum insulin, adipokines, AMP-activated protein kinase, and heat shock signal molecules in dairy cows. J Zhejiang Univ Sci B 16: 541-548.

10. Martins IJ (2015) Nutritional and Genotoxic Stress Contributes to Diabetes and Neurodegenerative Diseases such as Parkinson's and Alzheimer's Diseases. In: Atta-ur-Rahman (ed.). Frontiers in Clinical Drug Research - CNS and Neurological Disorders. Bentham Science. Pg no: 158-192.
11. Choukem SP, Gautier JF (2008) How to measure hepatic insulin resistance? Diabetes Metab 34: 664-673.

12. Martins IJ (2016) Heat shock gene Sirtuin 1 regulates post-prandial lipid metabolism with relevance to nutrition and appetite regulation in diabetes. International Journal of Diabetes and Clinical Diagnosis. Int J Diab Clin Diagn 3: 120 .

13. Martins IJ (2016) Bacterial Lipopolysaccharides Change Membrane Fluidity with Relevance to Phospholipid and Amyloid Beta Dynamics in Alzheimer's Disease. J Microb Biochem Technol 8: 322-324.

14. Martins IJ (2016) Geriatric Medicine and Heat Shock Gene Therapy in Global Populations. Curr Updates Gerontol 1: 1-5.

15. Martins IJ (2016) Type 3 diabetes with links to NAFLD and Other Chronic Diseases in the Western World. Int J Diab 1: 1-5.

16. Martins IJ (2016) Anti-Aging Genes Improve Appetite Regulation and Reverse Cell Senescence and Apoptosis in Global Populations. Advances in Aging Research 5: 9-26.

17. Martins IJ (2015) Diabetes and Organ Dysfunction in the Developing and Developed World Global Journals Inc 15: 1-9.

18. Anckar J, Sistonen L (2011) Regulation of HSF1 function in the heat stress response: implications in aging and disease. Annu Rev Biochem 80: 10891115.

19. Westerheide SD, Anckar J, Stevens SM Jr, Sistonen L, Morimoto RI (2009) Stress-inducible regulation of heat shock factor 1 by the deacetylase SIRT1. Science 323: 1063-1066.

20. Wang HY, Fu JC, Lee YC, Lu PJ (2013) Hyperthermia stress activates heat shock protein expression via propyl isomerase 1 regulation with heat shock factor 1. Mol Cell Biol 33: 4889-4899.

21. Reinke H, Saini C, Fleury-Olela F, Dibner C, Benjamin IJ, et al. (2008) Differential display of DNA-binding proteins reveals heat-shock factor 1 as a circadian transcription factor. Genes Dev 22: 331-345

22. Teigen LE, Orczewska JI, McLaughlin J, O'Brien KM (2015) Cold acclimation increases levels of some heat shock protein and sirtuin isoforms in threespine stickleback. Comp Biochem Physiol A Mol Integr Physiol 188: 139-147.

23. Trinklein ND, Chen WC, Kingston RE, Myers RM (2004) Transcriptional regulation and binding of heat shock factor 1 and heat shock factor 2 to 32 human heat shock genes during thermal stress and differentiation. Cell Stress Chaperones 9: 21-28.

24. Tomita T, Hamazaki J, Hirayama S, McBurney MW, Yashiroda H, et al. (2015) Sirt1-deficiency causes defective protein quality control. Sci Rep 5: 12613.

25. Rensing L, Monnerjahn C (1996) Heat shock proteins and circadian rhythms. Chronobiol Int 13: 239-250.

26. Fukuyama T, Doi M, Matsuo M, Nishinaga H, Miyake S, et al. (2008) Circadian expression of 86 - and $84-\mathrm{kDa}$ heat shock proteins in the mouse suprachiasmatic nucleus. Biomed Res 29: 93-98.

27. Magrané J, Smith RC, Walsh K, Querfurth HW (2004) Heat shock protein 70 participates in the neuroprotective response to intracellularly expressed beta-amyloid in neurons. J Neurosci 24: 1700-1706.

28. Yenari MA, Giffard RG, Sapolsky RM, Steinberg GK (1999) The neuroprotective potential of heat shock protein 70 (HSP70). Mol Med Today 5: 525-531.

29. Ou JR, Tan MS, Xie AM, Yu JT, Tan L (2014) Heat shock protein 90 in Alzheimer's disease. Biomed Res Int 2014: 796869.

30. Wilhelmus MM, de Waal RM, Verbeek MM (2007) Heat shock proteins and amateur chaperones in amyloid-Beta accumulation and clearance in Alzheimer's disease. Mol Neurobiol 35: 203-216.

31. Kakimura J, Kitamura Y, Takata K, Umeki M, Suzuki S, et al. (2002) Microglial activation and amyloid-beta clearance induced by exogenous heat-shock proteins. FASEB J 16: 601-603.

32. Wang H, Tan MS, Lu RC, Yu JT, Tan L (2014) Heat shock proteins at the crossroads between cancer and Alzheimer's disease. Biomed Res Int 2014: 239164. 
33. Sawa T, Imamura T, Haruta T, Sasaoka T, Ishiki M, et al. (1996) Hsp70 family molecular chaperones and mutant insulin receptor: differential binding specificities of BiP and Hsp70/Hsc70 determines accumulation or degradation of insulin receptor. Biochem Biophys Res Commun 218: 449-453.

34. Zachayus JL, Benatmane S, Plas C (1996) Role of Hsp70 synthesis in the fate of the insulin-receptor complex after heat shock in cultured fetal hepatocytes. J Cell Biochem 61: 216-229.

35. Marucci A, Miscio G, Padovano L, Boonyasrisawat W, Florez JC, et al. (2009) The role of HSP70 on ENPP1 expression and insulin-receptor activation. J Mol Med (Berl) 87: 139-144.

36. Xie L, Helmerhorst E, Taddei K, Plewright B, Van Bronswijk W, et al. (2002) Alzheimer's beta-amyloid peptides compete for insulin binding to the insulin receptor. J Neurosci 22: 221

37. Zhao WQ, De Felice FG, Fernandez S, Chen H, Lambert MP, et al. (2008) Amyloid beta oligomers induce impairment of neuronal insulin receptors. FASEB J 22: 246-260

38. Feng Y, Huang W, Meng W, Jegga AG, Wang Y, et al. (2014) Heat shock improves Sca-1+ stem cell survival and directs ischemic cardiomyocytes toward a prosurvival phenotype via exosomal transfer: a critical role for HSF1/ miR-34a/HSP70 pathway. Stem Cells 32: 462-472.

39. Rokavec M, Li H, Jiang L, Hermeking H (2014) The p53/miR-34 axis in development and disease. J Mol Cell Biol 6: 214-230.

40. Ohnishi K, Ohnishi T (2001) Heat-induced p53-dependent signal transduction and its role in hyperthermic cancer therapy. Int J Hyperthermia 17: 415-427.

41. Ohnishi T, Ohnishi K, Takahashi A (2002) Glycerol restores heat-induced p53-dependent apoptosis of human glioblastoma cells bearing mutant p53. BMC Biotechnol 2: 6 .

42. Martins IJ (2016) The Role of Clinical Proteomics, Lipidomics, and Genomics in the Diagnosis of Alzheimer's Disease Proteomes 4.

43. Martins IJ (2015) Nutritional diets accelerate amyloid beta metabolism and prevent the induction of chronic diseases and Alzheimer's disease, ( $1^{\text {st }}$ edn), Photon ebooks.

44. Xu Q, Hu Y, Kleindienst R, Wick G (1997) Nitric oxide induces heat-shock protein 70 expression in vascular smooth muscle cells via activation of heat shock factor 1. J Clin Invest 100: 1089-1097.

45. Manucha W, Walles $P$ (2008) Hsp70/nitric oxide relationship in apoptotic modulation during obstructive nephropathy. Cell Stress Chaperones 13: 413420 .
46. Malyshev IYu, Bayda LA, Trifonov Al, Larionov NP, Kubrina LD, et al. (2000) Cross-talk between nitric oxide and HSP70 in the antihypotensive effect of adaptation to heat. Physiol Res 49: 99-105.

47. Berrou J, Fougeray S, Venot M, Chardiny V, Gautier JF, et al. (2013) Natura killer cell function, an important target for infection and tumor protection, is impaired in type 2 diabetes. PLoS One 8: 62418.

48. Martins IJ (2017) Defective Interplay between Adipose Tissue and Immune System Induces Non Alcoholic Fatty Liver Disease. Updates Nutr Disorders Ther 1: 1-5.

49. Jaiswal MK, Agrawal V, Jaiswal YK (2013) Lipopolysaccharide drives alternation of heat shock proteins and induces failure of blastocyst implantation in mouse. Biol Reprod 88: 162

50. Triantafilou M, Triantafilou K (2004) Heat-shock protein 70 and heat-shock protein 90 associate with Toll-like receptor 4 in response to bacterial lipopolysaccharide. Biochemical Society Transactions 32: 636-639.

51. Stulík J, Hernychová L, Macela A, Krocová Z, Kroca M (1999) Production of stress-inducible form of heat-shock protein 70 in mouse peritoneal adherent cells after in vivo infection by Francisella tularensis. Folia Microbiol (Praha) 44: 306-310.

52. Merchant M, Fleury L, Rutherford R, Paulissen M (2008) Effects of bacterial lipopolysaccharide on thermoregulation in green anole lizards (Anolis carolinensis). Vet Immunol Immunopathol 125: 176-181.

53. do Amaral JP, Marvin GA, Hutchison VH (2002) The influence of bacterial lipopolysaccharide on the thermoregulation of the box turtle Terrapene carolina. Physiol Biochem Zool 75: 273-282.

54. Charalambous BM, Stephens RC, Feavers IM, Montgomery HE (2007) Role of bacterial endotoxin in chronic heart failure: the gut of the matter. Shock 28: $15-23$.

55. Martins IJ (2015) Unhealthy Nutrigenomic Diets Accelerate NAFLD and Adiposity in Global communities. J Mol Genet Med 09: 162

56. Baumgard LH, Keating A, Ross JW, Rhoads RP (2015) Effects of heat stress on the immune system, metabolism and nutrient partitioning: implications on reproductive success. Rev. Bras. Reprod. Anim., Belo Horizonte 39: 173-183.

57. Muralidharan S, Mandrekar P (2013) Cellular stress response and innate immune signaling: integrating pathways in host defense and inflammation. $J$ Leukoc Biol 94: 1167-1184.

58. Han J, Xu X, Qin H, Liu A, Fan Z, et al. (2013) The molecular mechanism and potential role of heat shock-induced p53 protein accumulation. Mol Cell Biochem 378: 161-169. 